\title{
Women's life cycle and abortion decision in unintended pregnancies
}

\author{
S Sihvo, N Bajos, B Ducot, M Kaminski, and the Cocon Group
}

J Epidemiol Community Health 2003;57:601-605

See end of article for authors' affiliations

....................

Correspondence:

Dr S Sihvo, Department of

Public Health, PO Box 41,

00014 University of

Helsinki, Helsinki, Finland;

sinikka.sihvo@helsinki.fi

Accepted for publication 20 January 2003

\begin{abstract}
Objective: To study the impact of sociodemographic, financial, and reproductive factors and of characteristics related to intimate relationships on the decisions of women in different age groups about whether or not to continue an unintended pregnancy.

Design: Cross sectional population based survey.

Setting: Telephone interview survey between September 2000 and January 2001 in France. From a representative sample $(n=14704)$ of 18 to 44 year old women, those who in the past five years had an abortion or whose last pregnancy was unintended were oversampled (sampling fraction $=100 \%$, $n=1034$ ) while the other women were randomly selected (sampling fraction $=19 \%, n=1829$ ). Altogether, 2863 women answered the questionnaire.

Participants: All women whose last pregnancy was unintended and ended in induced abortion or birth $(\mathrm{n}=645)$.

Main results: Factors associated with the abortion decision varied strongly according to age. Younger women's abortion decisions were mainly related to being a student and being single. Wanting to stop childbearing when the desired number of children was achieved best explained the decision to have an abortion among 25 to 34 year old women. Older women chose abortion especially when childbearing did not fit their work situation or when the relationship with the partner was unstable. A high level of education of a woman and her partner increased the likelihood of abortion, especially among young women.

Conclusions: The impact of socioeconomic and relationship factors on the decision to have an abortion is not the same at different stages in life, and refers to the social representations and perceptions of what good conditions are for being a mother.
\end{abstract}

$E^{2}$ en in countries where contraception is commonly used and easily available, the number of unintended pregnancies remains high. ${ }^{1}$ A large proportion of these unintended pregnancies end in abortion. According to a population based survey from the United States, ${ }^{2} 54 \%$ of unintended pregnancies end in abortion (27\% of all pregnancies). In Eastern Europe 57\% of all pregnancies end in abortion, and the figure is $21 \%$ for the rest of Europe. ${ }^{1}$ In France, abortion rates are on an average level for Europe; there are about 3 induced abortions for every 10 live births. ${ }^{3}$ According to a 1988 national survey, nearly $40 \%$ of pregnancies in France are unintended. ${ }^{4}$

Reproductive preferences and behaviour vary with socioeconomic and demographic factors. Underlying the evident causes for abortion, a desire to postpone or to stop childbearing, are other factors that can have different kinds of impact on different subgroups of women. In the developed countries, most abortions are performed for a variety of social reasons. Marital status and parity are important when abortion decisions are made 5 as are issues of studies or work, financial problems, single parenthood and problems in the relationship, immaturity, and unsuitable life situation ${ }^{6-10}$ Usually women give more than one reason for terminating a pregnancy, reflecting the multidimensional nature of the situation. There has been growing interest in the role that partners play in women's reproduction decisions, and studies have demonstrated that they do influence women's perceptions of pregnancy and reproduction decisions..$^{68^{11-15}}$ Zabin et al showed that pregnancies that were not wanted with a particular partner were more than twice as likely to end in abortion as those that were wanted. ${ }^{13}$ In a Swedish study poor relationship with the partner was the most often mentioned motive for an abortion. ${ }^{8}$ Otherwise studies on the influence of partners' characteristics on abortion decisions are lacking.

Despite the sizeable amount of literature on abortion, understanding of the nature and interaction of the different factors influencing the decision to continue or terminate pregnancy remains limited. The existing literature has been described as "confusing" because of substantial contextual, theoretical, and methodological differences between studies. ${ }^{16}$ In the studies on determinants of abortion, only a limited number of factors have been investigated, insufficiently covering the situation of most women at the time of pregnancy. In this study we wanted to explore the variety of personal factors that shape women's decisions in case of unintended pregnancy at the same time: sociodemographic, financial and reproductive factors, and characteristics of the relationship with the partner on the abortion decision, as a function of the woman's age. The concept of life course seemed appropriate for the background context of the study as it takes into account the perceived cultural appropriateness of behaviour according to age, demographic position, and personal biography. ${ }^{17}$ It was hypothesised that the impact of these factors differ depending on the stage of the life course of the woman. The objective of this paper is to analyse factors affecting the decision to have an abortion instead of continuing pregnancy among women belonging to different age groups whose last pregnancy was unintended.

\section{METHODS}

A representative sample of 14704 women aged between 18 and 44 years was randomly selected from the telephone directory, stratified by region. If multiple eligible women were living in the household that was contacted, one woman was randomly selected. Some 3162 women refused to participate and 
567 were otherwise excluded (unreachable women, incomplete questionnaire). The response rate was $75 \%$. Women who in the past five years had an abortion or whose last pregnancy was unintended were all selected (sampling fraction $=100 \%$, $\mathrm{n}=1034$ ) while a fraction of the other women were randomly selected (sampling fraction $=19 \%, \mathrm{n}=1829$ ). Altogether, 2863 women answered the questionnaire.

\section{Sample for this study}

Of the 2863 women in the sample, 2235 women had had at least one pregnancy in their lifetime. The analysis was limited to the 722 women whose last pregnancy was unintended, whether this last pregnancy happened in the past five years or before. Pregnancies with outcomes other than birth or induced abortion were excluded $(n=77)$, leaving 645 pregnancies that ended either in live birth or in induced abortion.

\section{Questionnaire}

The questionnaire was designed to explore the sociodemographic, economic, and other circumstances around the most recent pregnancy. It was developed on the basis of the results of a qualitative study on unintended pregnancies, ${ }^{18}$ and has been tested on a sample of 800 women. ${ }^{19}$

Independently of the question about "unintended pregnancy in the past five years" asked at the beginning of the questionnaire, pregnancy intention was asked about for each of the pregnancies: "Did you intend to get pregnant (then)?", with the response options (1) You didn't think about it, (2) You don't remember anymore, (3) Not at all, (4) You intended to get pregnant later, (5) You intended to get pregnant earlier, (6) You intended to get pregnant at that moment. Closer examination of the data suggested that women who responded "did not think about it", "not at all", or "later" differed significantly from each other for both sociodemographic and reproductive characteristics. Therefore only women who gave "not at all" responses were treated as having had an unintended pregnancy.

The characteristics that were looked at for the women included age and marital status at the time of the studied pregnancy, education, income, country of birth, religion, financial and material difficulties at the time of pregnancy, and financial solvency without the partner. Factors related to work were work status at the time of the studied pregnancy, type of contract, how well the pregnancy fitted her work situation, how long she had worked before pregnancy, and her interest in her work. Reproductive characteristics examined were number of children before last pregnancy, number of years since previous birth, earlier induced abortions, and use of contraception when getting pregnant.

Characteristics of the partner were age, education, and work situation. Factors related to the relationship included duration of the relationship, situation in the relationship (stable, new, uncertain, no future, about to break up), and agreement with the partner about whether to continue or terminate the pregnancy.

\section{Analysis}

To take the sampling design into account in the analysis, each woman was given a sampling weight, equal to the product of the number of eligible women times the inverse of the sampling fraction. Furthermore, to obtain representative estimators for the whole French population, the weight of each woman was modified according to the under-representation (or over-representation) of the categories to which she belonged compared with the structure of the general population. ${ }^{20}$ The individual weights were adjusted in such a way that the marginal distributions for some important characteristics (age, marital status, occupation, level of education) were identical in the sample (with the final weights) and in the French population. This process is based on the hypothesis that the "missing women" in a category ( such as "20-24 years old", "single") behave in a way that is closer to the average of respondents of the same category than to the average of the whole sample.

Stratified analysis according to age $(<25,25-34, \geqslant 35$ years $)$ was used in order to study the impact of different factors in different stages of women's life cycle. The $\chi^{2}$ test was used to analyse the relation between the different factors related to decision (abortion compared with continuation of pregnancy) separately within each age group and for the study sample as a whole. Separate multivariate logistic regression models were run for each of the three age groups. All factors were entered simultaneously in the models. Variables selected for inclusion in the models were those statistically significant in the bivariate analysis, but time from previous birth could not be included because of small numbers in some cells. Based on earlier literature and the target of the study, two variables (level of education of the woman and age of the partner) were included although they were not statistically significant. A variable was created to combine women's work status and how the pregnancy fitted the work situation.

Weighting was used in all analyses because of the complex sampling design (here inequal probability of inclusion) as it influences estimators of both parameters and their variances. ${ }^{21}$ STATA software was used to compute representative estimators for the general population and to perform statistical tests adequately. ${ }^{22}$

\section{RESULTS}

Nearly half $(48 \%)$ of the unintended pregnancies ended in birth, 38\% in induced abortion and the rest on other pregnancy outcomes.

\section{Bivariate analysis}

Several factors were associated with the decision to terminate or continue an unintended pregnancy in the separate bivariate analysis for each variable. Singlehood, higher education of the partner, student status among the women and their partners, unemployment among women, work situation, problems in the relationship, and number of children were all statistically significant factors in the decision to terminate the pregnancy (table 1). Among younger women, unintended pregnancies were more commonly terminated when the educational level of a woman and her partner was high, or either one of them was a student. Pregnancies were more likely to end in abortion if the woman wanted an abortion but her partner did not. Among 25-34 year old women, having an abortion was linked to reproductive characteristics; the proportion of women having an abortion was lowest for women with one child. Furthermore, 9 of 10 pregnancies were terminated among women who had a baby during the previous year.

Among older women ( $\geqslant 35$ years), having an abortion was most clearly related to the woman's work situation and to the relationship with the partner. Abortion was chosen in 9 of 10 cases when the work situation was not suitable to becoming pregnant. When the relationship had lasted for less than five years or when it was unstable, most of the pregnancies were terminated. In the case of disagreement between the couple, the pregnancy ended in abortion nearly always if the woman wanted an abortion even if her partner did not agree. Abortion was more common among older women who were single, had at least a high school education, and whose partner was highly educated.

Globally, no statistically significant differences were found between women terminating or continuing an unintended pregnancy for the following factors: nationality, religion, income, financial difficulties, financial solvency without the partner, type of work contract, how long she had worked before pregnancy, and interest in her work. 
Table 1 Proportion of women who had an abortion when last pregnancy was unintended according to sociodemographic and reproductive characteristics and to factors related to the relationship, by age groups (\%)

\begin{tabular}{|c|c|c|c|c|c|c|c|c|}
\hline & \multicolumn{8}{|c|}{ Age of the women at the time of the last pregnancy } \\
\hline & \multicolumn{2}{|c|}{$<25$ years } & \multicolumn{2}{|c|}{$25-34$ years } & \multicolumn{2}{|c|}{$\geqslant 35$ years } & \multicolumn{2}{|l|}{ Total } \\
\hline & $n=141$ & $\%$ & $\mathrm{n}=350$ & $\%$ & $\mathrm{n}=154$ & $\%$ & $\mathrm{n}=645$ & $\%$ \\
\hline \multicolumn{9}{|l|}{ Sociodemographic characteristics } \\
\hline Marital status & & & & & & ** & & * \\
\hline Married & 21 & 18 & 175 & 43 & 104 & 38 & 300 & 39 \\
\hline Co-habitant & 41 & 36 & 100 & 39 & 25 & 44 & 166 & 39 \\
\hline Single & 66 & 60 & 55 & 52 & 21 & 96 & 142 & 62 \\
\hline No information & 13 & 41 & 20 & 50 & 4 & 84 & 37 & 47 \\
\hline Age of the partner & & & & & & ** & & \\
\hline$<25$ & 68 & 36 & 12 & 26 & - & - & 80 & 35 \\
\hline $25-29$ & 46 & 48 & 86 & 38 & 6 & 3 & 138 & 37 \\
\hline $30-34$ & 23 & 62 & 139 & 44 & 26 & 52 & 188 & 46 \\
\hline $35-39$ & 3 & 20 & 76 & 42 & 63 & 58 & 142 & 46 \\
\hline$\geqslant 40$ & 1 & 100 & 37 & 64 & 59 & 64 & 97 & 65 \\
\hline Education of the woman & & ** & & & & ** & & \\
\hline No/minimum qualification & 21 & 19 & 87 & 48 & 31 & 32 & 139 & 40 \\
\hline Less than high school & 38 & 41 & 110 & 39 & 39 & 51 & 187 & 41 \\
\hline High school or +2 years & 59 & 62 & 100 & 35 & 57 & 80 & 216 & 53 \\
\hline Higher education & 23 & 86 & 53 & 45 & 27 & 58 & 103 & 58 \\
\hline Education of the partner & & $* *$ & & & & ** & & * \\
\hline No/minimum qualification & 20 & 17 & 48 & 42 & 17 & 8 & 85 & 30 \\
\hline Less than high school & 31 & 30 & 125 & 36 & 45 & 60 & 201 & 39 \\
\hline High school or +2 years & 45 & 73 & 77 & 50 & 27 & 65 & 149 & 59 \\
\hline Higher education & 13 & 76 & 43 & 46 & 40 & 75 & 96 & 64 \\
\hline Other/don't know/no response & 32 & 41 & 57 & 51 & 25 & 58 & 114 & 49 \\
\hline \multicolumn{9}{|l|}{ Material life conditions } \\
\hline Work status of the woman & & * & & & & $* * *$ & & * \\
\hline Working & 61 & 34 & 235 & 41 & 113 & 64 & 409 & 45 \\
\hline Student & 54 & 67 & 10 & 48 & - & - & 64 & 66 \\
\hline Unemployed & 9 & 54 & 20 & 72 & 7 & 82 & 36 & 69 \\
\hline Inactive & 16 & 19 & 85 & 42 & 34 & 13 & 135 & 33 \\
\hline Work status of the partner & & ** & & & & & & ** \\
\hline Working & 91 & 35 & 310 & 43 & 139 & 52 & 540 & 43 \\
\hline Student & 26 & 90 & 5 & 90 & - & - & 31 & 90 \\
\hline Unemployed/inactive & 21 & 37 & 33 & 49 & 15 & 29 & 69 & 40 \\
\hline How pregnancy fits to work situation & & * & & & & *** & & ** \\
\hline Not a good moment & 34 & 57 & 112 & 52 & 52 & 89 & 198 & 60 \\
\hline Well/didn't matter & 27 & 17 & 123 & 31 & 61 & 46 & 211 & 31 \\
\hline Not working & 80 & 48 & 115 & 47 & 41 & 22 & 236 & 44 \\
\hline \multicolumn{9}{|l|}{ Financial and material situation } \\
\hline Difficult & 50 & 32 & 133 & 49 & 53 & 51 & 236 & 47 \\
\hline Other & 91 & 46 & 217 & 40 & 101 & 48 & 409 & 43 \\
\hline \multicolumn{9}{|l|}{ Relationship } \\
\hline Duration of the relationship & & & & & & $* * *$ & & \\
\hline$\geqslant 5$ year & 11 & 13 & 143 & 49 & 79 & 36 & 233 & 43 \\
\hline $1-5$ & 40 & 52 & 68 & 43 & 18 & 84 & 126 & 51 \\
\hline$<1$ year & 66 & 49 & 54 & 61 & 13 & 94 & 133 & 57 \\
\hline Situation of the relationship & & & & & & *** & & * \\
\hline Stable & 59 & 33 & 242 & 37 & 120 & 36 & 421 & 36 \\
\hline New & 41 & 64 & 39 & 45 & 6 & 77 & 86 & 54 \\
\hline Uncertain & 19 & 30 & 26 & 63 & 14 & 94 & 59 & 56 \\
\hline No future/about to end & 22 & 61 & 42 & 60 & 14 & 100 & 78 & 65 \\
\hline Agreement with partner about abortion & & * & & & & $* \star *$ & & \\
\hline We agreed what to do & 89 & 43 & 230 & 38 & 110 & 40 & 429 & 39 \\
\hline I wanted abortion, he didn't & 17 & 71 & 33 & 59 & 13 & 91 & 63 & 67 \\
\hline I wanted to continue pregnancy, he didn't & 14 & 14 & 49 & 44 & 18 & 37 & 81 & 32 \\
\hline \multicolumn{9}{|l|}{ Reproductive characteristics } \\
\hline Number of children before & & & & *** & & & & ** \\
\hline 0 & 110 & 47 & 81 & 38 & 10 & 28 & 201 & 44 \\
\hline 1 & 23 & 26 & 101 & 16 & 24 & 67 & 148 & 25 \\
\hline 2 & 6 & 62 & 120 & 54 & 73 & 57 & 199 & 55 \\
\hline$\geqslant 3$ & 3 & 49 & 48 & 65 & 47 & 36 & 97 & 54 \\
\hline \multicolumn{9}{|l|}{ Time from previous birth } \\
\hline$<1$ year & 1 & 100 & 11 & 93 & - & - & 12 & 93 \\
\hline $1-2$ & 20 & 32 & 101 & 44 & 30 & 42 & 151 & 42 \\
\hline$>3$ years & 10 & 21 & 154 & 42 & 114 & 52 & 278 & 44 \\
\hline No children/earlier births & 112 & 47 & 81 & 36 & 10 & 28 & 201 & 43 \\
\hline
\end{tabular}

\section{Multivariate analysis}

The multivariate models confirmed that factors influencing the decision to have an abortion in unintended pregnancy varied by age. Younger ( $\leqslant 25$ years) women's abortion decision were mainly related to being a single (table 2). Higher educational level of herself and/or the partner, being a student, or having an unsuitable time to get pregnant because of work situation also increased the likelihood of abortion among youngest women. 


\begin{tabular}{|c|c|c|c|c|c|c|}
\hline & \multicolumn{6}{|c|}{ Age of the woman at the time of last pregnancy } \\
\hline & \multicolumn{2}{|c|}{$<25(n=140)$} & \multicolumn{2}{|c|}{$25-34(n=349)$} & \multicolumn{2}{|c|}{$\geqslant 35(n=154)$} \\
\hline & OR & $95 \% \mathrm{Cl}$ & OR & $95 \% \mathrm{Cl}$ & OR & $95 \% \mathrm{Cl}$ \\
\hline Marital status, married & 1.0 & & 1.0 & & 1.0 & \\
\hline Co-habitant & 4.8 & 0.5 to 46.2 & 1.8 & 0.8 to 3.9 & 2.2 & 0.3 to 15.5 \\
\hline Single & 17.2 & 1.9 to 156.8 & 2.0 & 0.6 to 6.4 & 13.8 & 0.9 to 195.1 \\
\hline No information & 5.2 & 0.5 to 59.2 & 1.3 & 0.3 to 5.8 & 0.7 & 0.01 to 35.2 \\
\hline Education, less than high school & 1.0 & & 1.0 & & 1.0 & \\
\hline High school or more & 3.7 & 1.1 to 12.4 & 0.8 & 0.4 to 1.6 & 5.5 & 1.6 to 19.1 \\
\hline Work status, working and good moment to get pregnant or it didn't matter 1) & 1.0 & & 1.0 & & 1.0 & \\
\hline Working, not a good moment to get pregnant & 5.8 & 1.0 to 34.5 & 2.1 & 0.8 to 5.7 & 10.8 & 2.4 to 49.5 \\
\hline Inactive (student, housewife, other) & 6.2 & 1.6 to 24.5 & 1.5 & 0.6 to 3.6 & 0.7 & 0.2 to 2.2 \\
\hline Age of the partner (continuous) & 1.1 & 0.9 to 1.2 & 1.0 & 1.0 to 1.1 & 1.1 & 1.0 to 1.1 \\
\hline Education of the partner, < high school & 1.0 & & 1.0 & & 1.0 & \\
\hline high school or more & 6.4 & 1.3 to 30.7 & 2.1 & 1.0 to 4.6 & 0.8 & 0.2 to 2.8 \\
\hline Work status of the partner, working & 1.0 & & 1.0 & & 1.0 & \\
\hline student, unemployed, other & 1.0 & 0.3 to 4.1 & 1.0 & 0.3 to 2.9 & 0.3 & 0.02 to 3.9 \\
\hline Relationship, stable & 1.0 & & 1.0 & & 1.0 & \\
\hline unstable & 0.8 & 0.2 to 2.8 & 3.3 & 1.2 to 9.2 & 12.1 & 1.6 to 92.3 \\
\hline Number of children before, $0-1$ & 1.0 & & 1.0 & & 1.0 & \\
\hline$\geqslant 2$ children & 9.0 & 0.6 to 137.3 & 7.6 & 3.8 to 14.9 & 3.1 & 0.7 to 12.9 \\
\hline
\end{tabular}

All variables entered into the model simultaneously. Woman's work status: $<25$ years $\chi^{2}=6.9, p<0.05 ; 25-34$ years $\chi^{2}=4.6$ non-significant; $\geqslant 35$ years $\chi^{2}=17.8 p<0.001$.

Among 25-34 year old women, the abortion was more likely to occur when the woman had already two children; the odds ratios were 0.62 (95\% CI 0.25 to 1.56 ) if the woman had one child and 4.4 (95\%CI 1.65 to 11.77 ) for women who already had two or more children, in comparison to women with no children. Similarly, unstable relationship and partner's higher education increased the likelihood of abortion.

Among older women ( $\geqslant 35$ years), unstable relationship also increased the likelihood of abortion as well as unsuitable work situation, higher education, and being single. The confidence intervals of single women and women with unstable relationships were, however, wide because of the small numbers of older women in these groups.

The results were not affected by period effects and they remained the same when "years from last unintended pregnancy" variable was added into the models.

\section{DISCUSSION}

The impact of socioeconomic characteristics, work, reproductive history, and factors related to the relationship on a woman's abortion decision varies according to the different phases of the life cycle of women. For younger women the decision to have an abortion is mainly influenced by a wish to continue her studies or to start work. In other research, women have stated unfinished studies to be a reason for abortion ${ }^{89}$ although it is seldom given as the most important reason. ${ }^{6}$ The situation of women in the 25-34 year age group is different as this age range encompasses the maternity stage in women's life cycle. In 2001, the average age of French women at the time of giving birth was 29.4 years. ${ }^{23}$ Statistics show that family size in France has been very stable during the past 25 years, and today the average number of children is still around two. ${ }^{24}$ Those women among 25-34 year olds who had only one child had the lowest likelihood of choosing abortion. Many women in this age group, however, already had the desired number of children and wanted to end their childbearing and therefore chose to have an abortion.

An important finding is the strong influence of the work situation. Although some studies have suggested that work is an important reason for having an abortion ${ }^{89}$ this has not been sufficiently studied. Kero et al showed that work, studies, and existing children were together the most important reason for an abortion among Swedish women, but this study did not examine these factors separately. ${ }^{9}$ Our results show that when a pregnancy is perceived as not suitable for the work situation, it is an important factor that influences the decision to have an abortion, especially for older women.

Responses to direct questions about financial and material circumstances showed that these factors were not associated with the abortion decision. But among unemployed women, 7 of 10 pregnancies were terminated. Single parenthood seems not to be a desirable option, as earlier studies have shown. ${ }^{62526}$

Most studies have not paid attention to the characteristics of the partner. Among younger women, high education level of the partner was even more strongly associated with abortion than was education level of the woman. A study among teenage women also showed a positive association between the partner's education and the likelihood of abortion. ${ }^{15}$ It may be that higher education levels of the woman and her partner are markers of social class, and that it is more acceptable for them to "plan" their family and terminate a pregnancy when the time is not right to have children and the priority is to establish their careers. On the other hand, for young women with no plans for a career requiring an education, having a child is a way of gaining a social identity.

Earlier studies have shown how a partner's attitudes and support greatly influence the decision to continue or interrupt the pregnancy. ${ }^{82-14}$ Our results are consistent with the literature $^{13}$ : if the woman felt that the relationship did not have a future the pregnancy was more likely to be terminated. But pregnancies were also likely to be terminated when the relationship was just beginning. Half of the pregnancies that occurred in uncertain or new relationships were terminated.

There was more agreement between the couple when an unintended pregnancy was continued than when it ended in abortion. When the woman stated that she wanted an abortion but her partner did not, the pregnancy was terminated in most cases. The group of 25 to 34 year old women were more often influenced by their partner's wishes about terminating or continuing the pregnancy than were younger or older women. According to a Swedish study between $6 \%$ and $10 \%$ of women were influenced by someone (mostly by their partners) when deciding about abortion. ${ }^{27}$ 
Another Swedish study gave some evidence that counselling before abortion can lead women in all age groups to continue their pregnancies when the initial reason for seeking an abortion was that the partner did not want a baby. ${ }^{6}$

Because of the retrospective nature of this study, recall biases are a possible issue. Our definition of unintended pregnancy was strict compared with other studies ${ }^{28}$ and factors related to the decision to have an abortion may be different for mistimed pregnancies. Our decision to exclude women with mistimed pregnancies was justified as the sociodemographic and reproductive characteristics of the former were closer to those of women with intended than unintended pregnancies (unpublished data). Another limitation is under-reporting of abortions, which can vary in surveys between $29 \%$ and $59 \%{ }^{29}$ Evidence from the pilot survey ${ }^{19}$ suggested that underreporting of abortions with this method is around $40 \%$, which may affect the conclusions drawn about the circumstances around abortion. Under reporting has been found to be significantly more common among young and unmarried women, where it can be around $60 \% .{ }^{29}{ }^{30}$

This population based study shows that there are several factors that influence the decision to have an abortion in case of unintended pregnancy, and that the impact of these factors varies according to age. It is evident that in addition to all these socioeconomic, reproductive, and other personal factors, the decision to continue or terminate pregnancy is influenced by the sociocultural context of the woman or couple. Studies trying to integrate macro contexts in analyses are very rare. ${ }^{31}$ In our study the role of social norms related to maternity appear clearly for the 25 to 34 year-old women, the group in which abortion was chosen less often, whose abortion decisions were mainly influenced either by the fact that they were in the most reproductive stage of their life cycle or by the fact that they already had the wanted and acceptable family size, two children. ${ }^{24}$ Younger women are also influenced by social norms at a stage where studies and professional issues are prioritised over parental life for those who wish to build careers. Whether there is a generation effect present that influences women's decision on abortion at different ages remains unanswered. More will be known when the youngest cohort now emphasising education and career come to the end of their reproductive life cycle.

\section{Authors' affiliations}

S Sihvo, Department of Public Health, University of Helsinki, Helsinki, Finland

S Sihvo, N Bajos, B Ducot, the Cocon Group, National Institute of Health and Medical Research (Inserm), Hospital of Bicêtre, Kremlin-Bicêtre, France

M Kaminski, National Institute of Health and Medical Research (Inserm), Villejuif, France

CONCON Group, Jean Bouyer, Michèle Ferrand, Hélène Goulard, Danielle Hassoun, Nadine Job-Spira, Nathalie Lelong, Henri Leridon, Caroline Moreau, Pascale Oustry, Josiane Warszawski.

Funding: the COCON survey was carried out with the financial support of Wyeth-Lederlé Laboratory, and this study was supported by a grant from INSERM.

Conflicts of interest: none.

\section{REFERENCES}

1 Alan Guttmacher Institute. Sharing responsibility-women, society and abortion worldwide. Report, Alan Guttmacher Institute 1999.

(www.agi-usa.org)
2 Henshaw SK. Unintended pregnancy in the United States. Fam Plan Perspect 1998;30:24-29, 46.

3 Prioux F. L'évolution démographique récente en France [The recent demographic evolution of France, English abstract]. Population 2001;56:571-610

4 Toulemon L, Leridon H. Maîtrise de le fécondité et appartenance sociale. Population 1992;47:1-46

5 Skjeldestad FE, Borgan J-K, Dalveit AK, et al. Induced abortion. Effects of marital status, age and parity on choice of pregnancy termination. Acta Obstet Gynecol Scand 1994;73:255-60.

6 Söderberg $\mathbf{H}$, Andersson C, Janzon L, et al.Continued pregnancy among abortion applicants. Acta Obstet Gynecol Scand 1997;76:942-7.

7 Torres A, Forrest JD. Why do women have abortions? Fam Plann Perspect 1988;20:169-76.

8 Törnbom $M$, Ingelhammar $\mathrm{E}$, Lilja $\mathrm{H}$, et al. Evaluation of stated motives for legal abortion. J Psychosom Obstet Gynecol 1994;15:27-33.

9 Kero A, Högberg U, Jakobsson L, et al. Legal abortion: a painful necessity. Soc Sci Med 2001;53:1481-90.

10 Larsson M, Aneblom G, Odling V, et al. Reasons for pregnancy termination, contraceptive habits and contraceptive failure among Swedish women requesting an early pregnancy termination. Acta Obstet Gynecol Scand 2002;81:64-71.

11 Fischer RC, Stanford JB, Jameson P, et al. Exploring the concepts of intended, planned, and wanted pregnancy. J Fam Pract 1999;48:117-22.

12 Kroelinger CD, Oths KS. Partner support and pregnancy wantedness. Birth 2000;27:112-19.

13 Zabin LS, Huggins GR, Emerson MR, et al. Partner effects on a woman's intention to conceive: 'not with this partner'. Fam Plann Perspect 2000;32:39-45.

14 Evans A. The influence of significant others on Australian teenagers' decisions about pregnancy resolution. Fam Plann Perspect 2001;33:224-30.

15 Zavodny M. The effect of partners' characteristics on teenage pregnancy and its resolution. Fam Plann Perspect $2001 ; 33: 192-205$.

16 Allanson S, Astbury J. The abortion decision: reasons and ambivalence. J Psychosom Obstet Gynecol 1995; 16:123-36.

17 Backett KC, Davison C. Lifecourse and lifestyle: the social and cultural location of health behaviours. Soc Sci Med 1995;40:629-38

18 Bajos N, Ferrand M et l'équipe GINE. De la contraception à l'avortement, Sociologie des grossesses non prévues. Paris: Editions INSERM, 2002

19 Houzard S, Bajos N, Warszawski J, et al. Analysis of the underestimation of induced abortions in a survey of the general population in France. Eur J Contracept Reprod Health Care 2000;5:52-60

20 Leridon H. Sample obtained: characteristics and adjustment. In: Spira A, Bajos N, ASCF Group. Sexual behaviour and AIDS. London: Avebury, 1994:69-76.

21 Skinner CJ, Holt D, Smith TM, eds. Analysis of complex surveys. New York: Wiley, 1989

22 Stata Corporation. (http://www.stata.com

23 Institut National d'Etudes Démographic. http://www.ined.fr. (accessed 17 Sep 2002).

24 Toulemon L, Mazuy M. Les naissances sont retardées mais la fécondité est stable [Childbearing is delayed but fertility is stable, English abstract] Population 2001;56:611-44.

25 Skjeldestad FE. When pregnant-Why induced abortion? Scand J Soc Med 1994;22:68-73

26 Barrett G, Peacock J, Victor CR. Are women who have abortions different from those who do not? A secondary analysis of the 1990 national survey of sexual attitudes and lifestyles. Public Health 1998;1 12:157-63

27 Törnbom $M$, Ingelhammar $E$, Lilja $H$, et al. Decision-making about unwanted pregnancy. Acta Obstet Gynecol Scand 1999;78:636-41.

28 Kaufman RB, Morris L, Spitz AM. Comparison of two question sequences for assessing pregnancy intentions. Am J Epidemiol 1997; 145:810-16.

29 Jagannathan $\mathbf{R}$. Relying on surveys to understand abortion behavior: some cautionary evidence. Am J Public Health 2001;91:1825-31.

30 Jones EF, Darroch Forrest J. Underreporting of abortion in survey of US women: 1976 to 1988. Demography 1992;29:113-26.

31 Remenneick LI, Segal R. Socio-cultural context and women's experiences of abortion: Israeli women and Russian immigrants compared. Culture, Health and Sexuality 2001;3:49-66. 